\title{
Academic Status of Plastic Surgery in the United States and the Relevance of Independence
}

\section{Zum aktuellen Status der akademischen Plastischen Chirurgie in den USA und der Bedeutung der strukturellen Unabhängigkeit}

Authors

Affiliations

\author{
P. Liu ${ }^{1}$, M. Singh ${ }^{2}$, E. Eriksson
}

${ }^{1}$ Department of Plastic Surgery, Rhode Island Hospital, Providence

${ }^{2}$ Division of Plastic Surgery, Department of Surgery, Brigham \& Women's Hospital, Boston

\section{Key words \\ - plastic surgery \\ - academic status \\ - division \\ - department \\ - autonomy}

Schlüsselwörter

- Plastische Chirurgie

- akademischer Status

- Abteilung

- Klinik

- Unabhängigkeit

received $\quad$ 7.3.2016

accepted $\quad 13.3 .2016$

\section{Bïbliography}

DOI http://dx.doi.org/

10.1055/s-0042-104373

Handchir Mikrochir Plast Chir

2016; 48: 65-68

(c) Georg Thieme Verlag KG

Stuttgart · New York

ISSN 0722-1819

Correspondence

\section{Elof Eriksson, MD, PhD}

Chief of Division of Plastic Surgery

Brigham \& Women's Hospital

Boston

MA 02115

eeriksson@partners.org

\section{Abstract}

$\nabla$

Background: The basic administrative structures at most academic institutions were implemented more than 50 years ago and have remained largely unchanged. Since the surgical specialties were in nascent stages during that time, they were clubbed together within the department of surgery. There has been extensive growth in the breadth and depth of plastic surgery over the past few decades and current administrative structures might not truly reflect the current standing of plastic surgery.

Objectives: The goal of this article was to review the academic status of Plastic Surgery in the United States and assess the relevance of independence from the department of surgery.

Results: A national survey of 94 hospitals with plastic surgery residency training programs in the United States was conducted to investigate the academic status of plastic surgery. 25 out of those 94 programs had department status with their respective hospitals while another 9 programs were actively planning on transitioning to department status. Out of the 25 plastic surgery hospital departments, 17 programs were also University departments. The number of plastic surgery departments has more than doubled over the past 10 years and continues to rise as more plastic surgery divisions seek department status. Conclusions: There are multiple advantages to seeking department status such as financial and administrative autonomy, ability to participate in medical school curricula, easier access to interdepartmental institutes and faculties, parity with other specialties, and increased control of resident education. There has been concerted advocacy for separating from surgery departments and seeking independent departmental status for plastic surgery. However, the transition from a division to department is a slow and demanding process and requires a well-planned strategy.

\section{Zusammenfassung \\ $\nabla$}

Hintergrund: Die grundlegenden Organisationsstrukturen in den USA wurden in den meisten akademischen Einrichtungen vor mehr als 50 Jahren fest gelegt und blieben seither weitgehend unverändert. Da die einzelnen chirurgischen Fachgebiete gerade erst entstanden waren, wurden sie in einem Department für Chirurgie zusammen gefasst. In den letzten Jahrzehnten kam es zu einem starken Wachstum der Plastischen Chirurgie - sowohl in die Breite als auch in die Tiefe. Aus diesem Grund wurden die Organisationsstrukturen vielerorts noch nicht der Bedeutung der Plastischen Chirurgie angepasst. Ziele: Das Ziel der vorliegenden Arbeit war es den aktuellen Status der akademischen Plastischen Chirurgie in den USA zusammenzufassen und die Bedeutung der strukturellen Unabhängigkeit von der Allgemeinchirurgie zu bewerten. Ergebnisse: 94 Krankenhäuser mit einem Weiterbildungsprogramm für Plastische Chirurgie wurde ausgewertet, um den aktuellen Status der akademischen Plastischen Chirurgie in den USA zu untersuchen. 25 dieser 94 Einrichtungen hatten den Status eines eigenständigen Departments und weitere 9 befanden sich in der aktiven Planung einer eigenständigen Departments. Von den 25 eigenständigen Departments waren 17 auch eigenständige Departments einer Universität, in Deutschland vergleichbar mit eigenständigen Kliniken ausgestattet mit W3 Professuren. Die Zahl der eigenständigen Departments für Plastische Chirurgie hat sich in den letzten 10 Jahren mehr als verdoppelt und erhöht sich zunehmend mit mehr und mehr Sektionen, die den Status einer Klinik anstreben.

Schlussfolgerungen: Es gibt eine Vielzahl von Vorteilen den Status eines Departments anzustreben, Dazu zählt die verwaltungstechnische Unabhängigkeit, die Möglichkeit eigene Lehrpläne für das Fachgebiet im Rahmen des Medi- 
zinstudiums aufzustellen, ein leichterer Zugang zu gemeinsamen Instituten mehrerer Kliniken, die Augenhöhe mit anderen Fachgebieten und eine verbesserte Kontrolle der Weiterbildung. Es besteht Konsens in den USA, dass eine Abspaltung der Plastischen Chirurgie von den Departments für Chirurgie befürwortet wird. Trotzdem ist der Übergang von einer Sektion zu einer eigenständigen Klinik ein langsamer und schwieriger Prozess, der eine gut geplante Strategie benötigt.

\section{Background \\ $\nabla$}

The field of surgery has evolved significantly over the past few decades. However, the basic administrative structure at many medical schools, which were implemented in some cases centuries ago, remain largely unchanged [1]. During that era, surgical specialties were mere extensions of general surgery with additional interest in the desired subspecialty. The required skill set for surgical specialty training was small and all subspecialties generally included pre-requisite or substantial general surgery training. Given the significant overlap in training and practice of general surgeons and surgical specialties, they were pooled together under the department of surgery. The department chairman generally had some understanding of different specialties and resources were available to support one specialty without affecting other specialties. However, multiple surgical specialties have experienced significant growth since then and skill sets and turfs overlap posing a serious challenge to the relatively archaic administrative set up. Among different surgical specialties, the field of plastic surgery has experienced a meteoric rise over the past 50 years.

\section{Growth of Plastic Surgery in the United States $\nabla$}

Plastic Surgery developed as a mature and unique specialty during the middle of $20^{\text {th }}$ Century. The American Society of Plastic Surgeons (ASPS) was established in 1931 to advance quality care to plastic surgery patients by encouraging high standards of training, ethics, physician practice and research in plastic surgery [2]. The American Board of Plastic Surgery was established in 1938 in order to establish standards for education and certification in the new specialty [3]. The Plastic Surgery Research Council (PSRC) was established in 1955 and is primarily dedicated to research in the field of plastic surgery [4]. The National Endowment of Plastic surgery was also created to support plastic surgery research [5]. Furthermore, the Plastic Surgery (Educational) Foundation has been established to support plastic surgery continuing education. Over the past few decades, there have been major advances in the field of plastic and reconstructive surgery [6]. Advancement of microscopic techniques allowed reliable one-stage reconstruction of major complex deformities using free-tissue transfer of vascularized tissue from one part of the body to another. A better understanding of craniofacial anatomy and pathophysiology resulted in development of craniofacial surgery. The advent of Vascularized Composite Allotransplantation (VCA) resulted in successful full-face and hand transplantations and has generated significant recognition of the field of plastic surgery [7]. The rapid proliferation of subspecialty residency programs led to the establishment of a Plastic Surgery Residency Review Committee within the Accreditation Council for Graduate Medical Education (ACGME) [8]. With the rise of plastic surgery as a specialty, the overlap of training and practice between general surgeons and plastic surgeons decreased significantly. This resulted in the integrated model of plastic surgery residency that requires the resident's curriculum being overseen by the plastic surgery program director from day one of the residency. In addition, there are sub-specialization options in aesthetic surgery, craniofacial surgery, hand surgery and microsurgery after completing plastic surgery training [9].

\section{Organizational Structure of Plastic Surgery in the United States $\nabla$}

As the scope of plastic surgery broadened, there has been increased sense of need in the field of plastic surgery for more administrative autonomy [10-12]. The primary administrative unit in most medical schools is a department. Each department in a medical school represents its basic science and clinical discipline. The key decisions regarding institutional strategies and allocation of resources involve the department chair. On the other hand, the rights and representation as a 'division chief' is limited and can be overruled by the 'department chief' if the vision and budget of the plastic surgery division is not in tune with the department chief. Because of the increasing gap between the scope and outreach of general surgery and plastic surgery, it is possible that the department of surgery might not be able to represent the best interests of the division of plastic surgery. This can create a conflict of interest on the part of the department chief and minimize the autonomy and functioning of the division of plastic surgery. Because of these reasons, there has been a concerted advocacy for separating from surgery and seeking a department status for plastic surgery [10-12]. A national survey of 94 hospitals with plastic surgery residency training programs in the United States was conducted to investigate the academic status of the plastic surgery. 25 out of those 94 programs had department status in their respective hospitals while another 9 programs were actively planning on transitioning to department status ( $\bullet$ Table 1 ). For example, The University of South Florida Plastic Surgery program will transition to a department beginning July 1, 2016 at both the medical school and the affiliated hospital. Out of the 25 plastic surgery hospital departments, 17 programs were also University departments ( $\bullet$ Table 1 - top/ bold). At the Cleveland Clinic, which is listed as a hospital Department, Plastic Surgery is coupled with Dermatology. The number of plastic surgery departments has more than doubled over past 10 years and continues to be on the rise as more plastic surgery divisions seek department status. The exponential growth and outreach of plastic surgery can also be gauged from the fact that specialty hospitals such as Boston Children Hospital and MD Anderson Cancer Center have separate Departments of Plastic Surgery. 
Table 1 List of Plastic Surgery Hospital Departments in the United States. Out of the 25 Plastic Surgery Hospital Departments, (top/bold) 17 programs are also University Departments.

\begin{tabular}{l} 
Case Western Reserve University/University Hospitals Case Medical \\
Center \\
Johns Hopkins University/University of Maryland/The Johns Hopkins \\
Hospital \\
Loma Linda University Program/Medical Center \\
Medical College of Wisconsin Affiliated Hospitals Program \\
New York University School of Medicine/NYU Langone Medical Center \\
Ohio State University Medical Program/OSU Medical Center \\
Rush University Medical Center Program \\
\hline University of California (Irvine) Program/Medical Center \\
University of Kansas School of Medicine Program \\
University of Tennessee College of Medicine at Chattanooga Program \\
University of Tennessee Health Science Center \\
University of Texas Southwestern Medical School Program \\
University of Virginia Program/UVA Health System \\
University of Pittsburgh Medical Education Program \\
Vanderbilt University Program \\
Wake Forest School of Medicine \\
Wright State University \\
Brown University Program/Rhode Island Hospital \\
\hline Carolinas Medical Center Program/Carolinas Medical Center \\
Children's Hospital Boston/Harvard Medical School Program \\
Cleveland Clinic (Florida) Program \\
Cleveland Clinic Foundation Program/Cleveland Clinic \\
Lahey Clinic Program/Lahey Clinic \\
MD Anderson Cancer Center (UT Houston) \\
Southern Illinois Hospital \\
\hline
\end{tabular}

\section{Advantages of Transitioning to Department Status}

\section{$\nabla$}

There are significant advantages to seeking a department status for plastic surgery $[1,10-12]$. A department of plastic surgery will have greater fiscal and administrative autonomy and may be able to serve its specialty's interest in a more meaningful manner. The increased fiscal autonomy will result in direct control over the patient and research related funds and minimize the revenue sharing with the department of surgery. It also allows direct negotiation for funding with various institutions and third party payors. The administrative autonomy eliminates multiple layers of bureaucracy and can result in increased access and influence on policy making and resource allocation in an academic organization.

Being a department assures plastic surgery a seat at the table with the Dean of the Medical School. Medical school curricula can benefit from the specialized and applied anatomical expertise plastic surgeons bring to their craft. In exchange, the Dean can assist in access to philanthropic efforts at the University level, and can facilitate cross-disciplinary Institutes involving plastic surgical faculty, with for example, stem cell scientists from the basic sciences.

Department status can also have major effect on clinical practice and training. There are multiple areas of overlap with specialties such as otolaryngology and orthopedics with regards to facial and hand trauma respectively. The department of surgery might not prioritize the interests of plastic surgery which can result in loss of clinical practice to other specialties, who might have greater influence if they are individual departments. The department status can level the playing field with such competing specialties and allow autonomous and independent growth of plastic surgery in an academic hospital. With regards to residency training, the chairman/program director of a plastic surgery di- vision might not be able to represent the resident's best interests on surgical services. As a division, it can be difficult to ensure the most desirable and beneficial clinical experience for the plastic surgery residents on surgery rotations. They might end up in less educationally beneficial surgical rotations, essentially serving the purpose of offloading general surgery residents of service on less sought-after rotations.

The research endeavors of plastic surgery division can also be adversely affected in the department of surgery. It may be less likely for a plastic surgery faculty member to receive support from the department of surgery to develop a translational or basic science research program in preference to a general surgeon, especially if the Chair of Surgery is not well-versed in key targets of plastic surgical research. The direction and funding of core research facilities is also more likely to be geared towards the requirements of general surgery researchers. A recent study demonstrated that faculty members of departments of plastic surgery publish more manuscripts than plastic surgeons in subordinate or dependent organizational structures [13].

\section{Blue-prints of Transitioning}

Conversion of a division to department is essential with exponential growth of the field of plastic surgery but it is a slow and demanding process and requires a well-planned strategy[1,10$12]$. It is critical to analyze the implications and potential roadblocks beforehand. There is no uniform template for conversion since the requirements can vary from one institution to another. However, few critical blueprints should be considered before setting on the journey for department status.

One of the hallmarks of a separate specialty is financial viability and independence. Strong growth in all the areas of plastic surgery will ensure constant patient flow which is essential to financial autonomy. It is also important to track the downstream fiscal effect of plastic surgery involvement in breast and extremity reconstruction, wound healing and similar areas of work where other specialties get primary credit both financially and academically. Plastic surgery profits might be getting overtly or covertly shunted to subsidize other less profitable divisions of the surgery department. Anticipating and developing a joint strategy with the Chair of Surgery to remediate this loss of subsidy for other loss-leading divisions may be a critical step in attaining financial independence. The Dean will certainly not want to handicap the Department of Surgery by "losing" plastic surgery. It is important to work closely with other specialties and develop camaraderie with them. Plastic surgery should be viewed as an effective and easily accessible option for all reconstructive consultations within the institution. This can further drive up the revenue and endorsement from other specialties can also strengthen the argument for department status. Prospects for plastic surgical independence may hinge on the ability of a cosmetic center to generate a revenue stream apart from insurance-based reimbursement.

Increasing the size of the faculty within fiscal restraints and based on sound profit and loss business planning can help address current and anticipated clinical needs in different aspects of reconstructive surgery, from microsurgery and breast reconstruction, to craniofacial, hand and pediatric surgery. The increased number of revenue generating surgeons addressing different aspects of plastic surgery can provide financial growth opportunities and can tap into underutilized clinical areas as sources of reimbursement. Additionally, the diversity in the 
practice of plastic surgery can further strengthen the argument that each branch of plastic surgery essentially functions as a division within the department of plastic surgery.

Plastic surgeons should be leaders in focused clinical, translational and basic science research work. Funding from National Institute of Health (NIH), Department of Defense (DOD) and other government and private agencies should be actively sought. A recognized research program is highly valued in an academic set up especially when extra mural funding provides significant over head (indirect) costs to the hospital. Strong organization support with a separate research division should be considered as a part of the long term goals. In fact, it is highly unlikely that departmental status would even be considered without strong extramural support (and indirects) flowing to plastic surgery.

Involvement of the faculty members in all the affairs of the medical school and healthcare organization can play a significant role in persuading the Dean to consider a department. Sufficient participation in the medical school through educating the medical students and serving on different committees can increase the visibility and reputation of the field. Administrative participation at all clinical levels in the institution can also provide a voice and recognition of plastic surgery. Another important way to gain recognition is to develop separate training program that has a core plastic surgical curriculum throughout. The development of integrated plastic surgery programs provides a sense of independence and better control and focus of the resident training.

The most appropriate time to convert a division to a department is when the hospital is conducting nation-wide search for new division chief. In 2006, the Association of Academic Chairmen of Plastic surgery voted and affirmed that any new faculty member who is being interviewed for the position of chief of plastic surgery in the United States must have a commitment that plastic surgery becomes a department within a specific timeline in the near future [11]. As an example, the Johns Hopkins Plastic surgery program was granted a department status in 2010 as a part of transition plans when Dr. Andrew Lee was recruited as the new chief. It is possible that the plastic surgery division, while searching for a new chief, might have only few faculty members and conversion to a department might be financially non-viable. It is still worth negotiating the goals and objectives with the understanding that achieving those goals at a future time point would be rewarded with department status.

\section{Potential Pitfalls}

$\nabla$

While transitioning to department status can provide fiscal and administrative autonomy, caution should be warranted against overtly eager or ill-prepared transition. Financial independence needs to ensure in the short term and long term before moving forward. A department of plastic surgery would possibly be more susceptible to financial risk than a plastic surgery division. A business plan is mandated in such scenarios. There needs to be a well designed short-term and long term planning with an objective annual template to measure growth and development. Annual clinical and research strategic planning meetings should be conducted to assess the progress from last year and set the goals for the forthcoming year.

\section{Conclusions}

$\nabla$

The current administrative structure of the surgery department in most academic institutions was established more than 50 years ago and does not account for the exponential growth of the field of plastic surgery over the past few decades. There has been concerted advocacy for separation from surgery departments and seeking independent department status for plastic surgery. The number of plastic surgery programs with department status has more than doubled over the past 10 years and continues to be on the rise as more plastic surgery divisions seek department status. There are multiple advantages to seeking a department status such as financial and administrative autonomy, greater importance at the medical school, parity with other specialties and increased control of resident education. However, the transition from a division to department is a slow and demanding process and requires a well-planned strategy.

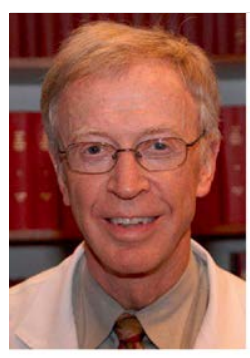

Dr. Elof Eriksson born in Backe, Sweden. Attended medical school, finished his PhD in Anatomy and Physiology and worked as a surgical intern at University of Goteborg. Completed general surgery residency at University of Chicago Hospitals and plastic surgery fellowship at Medical College of Virginia. Before moving to Boston, assistant professor of surgery at University of Goteborg and associate professor of surgery at Southern Illinois University of Medicine. He also served as Chairman of Department of Plastic Surgery at Memorial Medical Center, Springfield, IL. In plastic surgery he has published more than 200 peerreviewed manuscripts and has contributed to multiple books. Chief of the Division of Plastic Surgery at Brigham \& Women's Hospital (BWH), Harvard Medical School for the past 29 years. Served as director of American Board of Plastic Surgery and is the president elect of Wound healing society. He and his wife are parents of 3 daughters and 1 son.

Conflict of Interest and Financial disclosure: None.

\section{References}

1 Lawrence WT, Rohrich RJ, Larson DL et al. Association of academic chairmen of plastic surgery white paper on departmental status. Plast Reconstr Surg 2009; 124: 293-297

2 http://www.plasticsurgery.org/about-asps.html

3 Singh $M$, Noone $R B$, Afolabi $\mathrm{H}$ et al. A tribute to the founding figures of the American Board of Plastic Surgery. Plast Reconstr Surg 2015; 135: 1047e-1054e

4 http://ps-rc.org/about/brief-history.cgi

5 http://www.thepsf.org/research/psf-grant-funding/national-endow ment-for-plastic-surgery.htm

6 McDonald HD, Vasconez LO. Advances in plastic surgery. West J Med 1982; 136: 23-28

7 Pomahac B, Pribaz J, Eriksson E et al. Three patients with full facial transplantation. N Engl J Med 2012; 366: 715-722

8 https://www.acgme.org/acgmeweb/tabid/145/ProgramandInstitu tionalAccreditation/SurgicalSpecialties/PlasticSurgery.aspx

9 http://acaplasticsurgeons.org/fellowship-listing/

10 Guyuron B. Academic plastic surgery: division or department? Aesthet Surg J 2008; 28: 594-595

11 Rohrich RJ. Mandating Departments of Plastic Surgery: the future of plastic surgery is now. Plast Reconstr Surg 2008; 121: 1499-1502

12 Rohrich RJ, Larson DL. The future of plastic surgery in academic medical centers: making the case for autonomous departments of plastic surgery. Plast Reconstr Surg 1997; 100: 761-763

13 Schubert CD, Leitsch S, Haertnagl F et al. Independence in Plastic Surgery - Benefit or Barrier? Analysis of the Publication Performance in Academic Plastic Surgery Depending on Varying Organisational Structures. Handchir Mikrochir Plast Chir 2015; 47: 213-221 